\title{
Indications and reasons for discontinuing the levonorgestrel-releasing intrauterine system (LNG-IUS)
}

Maria Luíza Lemos Pires 1

iD https://orcid.org/0000-0003-0615-7669

Ariani Impieri Souza 2

https://orcid.org/0000-0002-7917-5983

Maria Luisa Borges Roriz Dantas 3

https://orcid.org/0000-0001-7829-8204

Gabriela Delgado Soriano 4

https://orcid.org/0000-0002-3360-8317
Cláudia Viana Henriques 5

(iD) https://orcid.org/0000-0002-7165-543X

Ana Laura Carneiro Gomes Ferreira 6

D https://orcid.org/0000-0001-9172-6162

1,3,4 Faculdade Pernambucana de Saúde. Recife, PE, Brasil.

2,5,6 Departamento de Ginecologia e Obstetrícia. Instituto de Medicina Integral Professor Fernando Figueira. Rua dos Coelhos, 300. Boa Vista. Recife, PE, Brasil. CEP: 50.070-550. E-mail: ariani@imip.org.br

\begin{abstract}
Objectives: to identify the main indications and reasons for discontinuing the use of the Levonorgestrel-Releasing Intrauterine System (LNG-IUS).

Methods: a cross-sectional study was carried out from medical records of 327 women who used the LNG-IUS 52mg between January 2011 and December 2016 at a public hospital in the Northeast of Brazil.

Results: the main indications for the use of the LNG-IUS were: contraception (32.7\%), myoma/metrorrhagia (28.7\%) and endometriosis/pelvic pain (22.3\%). Of the 327 women, 68 (20.8\%) had discontinued using the device. The most frequent reasons for discontinuation were: expulsion (9.2\%), LNG-IUS expiration (3.7\%), bleeding (2.4\%) and pain (1.5\%). Most patients had no difficulty in the insertion and did not require anesthesia/sedation. Among the 30 women who expelled the device, 17 (56.7\%) had used it for metrorrhagia and myoma, 8 (26.7\%) for contraception, and 5 (16.6\%) for endometriosis/pelvic pain.

Conclusions: the LNG-IUS is a well-accepted contraceptive method, with therapeutic applications for some gynecological conditions and a low expulsion rate.

Key words Contraception, Contraceptive effectiveness, Levonorgestrel, Long-acting reversible contraception, Progesterone-releasing intrauterine devices
\end{abstract}

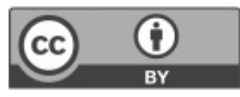




\section{Introduction}

The Levonorgestrel-Releasing Intrauterine System (LNG-IUS) was initially developed as a device for contraception. Its use is now recommended by the World Health Organization (WHO), and it is considered one of the most effective long-acting reversible contraception (LARC) methods. ${ }^{1,2}$

In the mid-1990s, the LNG-IUS was proven to be an effective treatment for menorrhagia and dysmenorrhea owing to its inhibitory effect on endometrial actions with consequent atrophy and a decrease in the thickness of the uterine endometrium. 3,4

Non-contraceptive benefits of the LNG-IUS, including treatment of abnormal uterine bleeding, were reported in a systematic review conducted in 2015.5 Currently the LNG-IUS is recommended as the first-line treatment for menorrhagia in the United Kingdom, and it is approved in 120 countries as a contraceptive method and in 115 countries to control menorrhagia. 6 Among other non-contraceptive uses, other researchers have reported proven benefits of the LNG-IUS in the management of dysmenorrhea by decreasing pelvic pain, premenstrual syndrome (PMS) and to treat endometriosis and adenomyosis. 7,8

On the basis of the WHO eligibility criteria, the LNG-IUS can be used safely by both multiparous and nulliparous women, as well as by women in other clinical situations. It is contraindicated in cases of suspected or confirmed breast cancer, malignant disease in the cervix, malformation or distortion of the uterine cavity, active pelvic infection, suspected or confirmed pregnancy, and uterine bleeding of unknown etiology. 8,9

Complications associated with the insertion of the LNG-IUS include uterine perforation, cervix laceration, inadequate device placement, and expulsion of the device. ${ }^{10}$ In addition to complications, other situations that make it difficult or impossible for LNG-IUS insertion include: stenosis of uterine cervix, distortion of the uterine cavity and pain. ${ }^{9}$ The postpartum period while women are still breastfeeding, history of cesarean delivery, and inexperience of the health professionals can also add to the previously mentioned difficulties. 10

The reasons for the removal of the LNG-IUS include changes related to menstrual bleeding pattern, and although less frequent, hormonal changes causing such as weight gain, acne and mastalgia.11,12 Expulsion is another reason for discontinuation of the use of the LNG-IUS. 13

In addition to expanding the contraceptive options available to women seeking effective, reversible, and safe methods, the LNG-IUS has been very cost-effective method. ${ }^{14,15}$ The study by Pepe et al. 15 showed that the LNG-IUS could be costeffective when compared with other hormonal methods. The present study aims to identify the main indications to use the LNG-IUS 52mg and the main reasons for discontinuation of use.

\section{Methods}

A cross-sectional observational study was carried out at the Instituto de Medicina Integral Prof. Fernando Figueira (IMIP). The medical records of 327 women who used the LNG-IUS between January 2011 and December 2016 were analyzed.

We collected the following information from the patients' medical records: sociodemographic variables (education, residence place, profession, and marital status), biological variables (date of birth, race, and disease status), reproductive/gynecological data (age of menarche, age at first intercourse, number of sexual partners, number of gestations, births, abortions and types of births) and LNG-IUS variables (date of insertion, physician who performed the insertion, indications, any difficulty in insertion, use of anesthesia/sedation, and continued use of the device or reason for discontinuation).

The data was entered into a database created on Microsoft Excel. The distribution of absolute and relative frequencies was performed by program $\mathrm{R}$, version 3.3.1. Pearson's chi-square test was applied to verify association between two variables. A $p$ value $<0.05$ was considered significant.

This project was approved by the Human Research Ethics Committee of IMIP, with CAAE No. 59253516.5.0000.5201.

\section{Results}

The mean age of the 327 women at the time of the LNG-IUS insertion was $35 \pm 8$ years, and 107 $(32.7 \%)$ had 8 to 11 years of schooling. The majority of the women $(n=256 ; 78.3 \%)$ came from the Metropolitan Region of Recife and 168 (51.4\%) were married or in a stable union. Only $56(17.1 \%)$ were nulliparous and among the parous, 153 (46.8\%) had a previous cesarean section (Table 1).

Among the main indications to use the LNG-IUS device, 107 women $(32.7 \%)$ chose this method for contraception; 94 (28.7\%) women chose for treating myoma and/or metrorrhagia; $73(22.3 \%)$ for endometriosis associated with pelvic pain, and 27 
$(8.3 \%)$ for hematological disease. Other indications $(\mathrm{n}=26 ; 8 \%)$, included post-abortion contraception, women with renal transplantation, and PMS.

Sixty eight $(20.8 \%)$ women discontinued the use of the LNG-IUS. Thirty (9.2\%) of them discontinued by expulsion, 8 (2.4\%) discontinued for bleeding and $5(1.5 \%)$ for pelvic pain. Other reasons for discontinuation $(n=13 ; 4.0 \%)$ included weight gain, acne and desire to have children. Finally, 12 women $(3.7 \%)$ wished to change the device at the end of LNG-IUS lifespan. Among the 30 women who expelled the device, 17 (56.7\%) had used it for metrorrhagia and myoma treatment (Table 2).
Difficulty in the insertion of the LNG-IUS occurred in $49(15.0 \%)$ women and only $15(4.6 \%)$ women were required anesthesia/sedation. Insertion difficulty was significantly associated with nulliparity $(p=0.002)$ and the need for anesthesia/sedation $(p=0.006)$. There was no association between the insertion difficulty and type of delivery $(p=0.060)$ (Table 3).

Table 1

Distribution of biological and sociodemographic characteristics among the women using the LNG-IUS.

\begin{tabular}{lcc}
\hline Variables & N=327 & $\%$ \\
\hline Age between 30-39 years old (mean age - 35 \pm years) & 137 & 41.9 \\
Schooling between 8-11 years & 107 & 32.7 \\
Living at Metropolitan Region of Recife & 256 & 78.3 \\
Married / stable union & 168 & 51.4 \\
Nulliparous & 56 & 17.1 \\
Parous & 269 & 82.2 \\
Previous cesarean section & 153 & 46.8
\end{tabular}

LNG-IUS = Levonorgestrel-Releasing Intrauterine System.

Table 2

\begin{tabular}{lcc}
\hline Distribution of the main indications to use the LNG-IUS and the main reasons for discontinuation of the LNG-IUS. & N=327 \\
\hline Main indications to use & 107 & 32.7 \\
\hline Contraception & 94 & 28.7 \\
Metrorrhagia / myoma & 73 & 22.3 \\
Endometriosis / pelvic pain & 27 & 8.3 \\
Hematological disease & 26 & 8.0 \\
Other indications & & 9.2 \\
Main reasons for discontinuation & 30 & 2.4 \\
Expulsion & 8 & 1.5 \\
Bleeding & 5 & 3.7 \\
Pelvic pain & 12 & 4.0 \\
End of LNG-IUS lifespan & 13 & \\
\hline
\end{tabular}

LNG-IUS = Levonorgestrel-Releasing Intrauterine System. 


\begin{tabular}{|c|c|c|c|c|c|c|c|}
\hline \multirow[t]{3}{*}{ Variables } & \multicolumn{4}{|c|}{ Difficulty in insertion } & \multirow{2}{*}{\multicolumn{2}{|c|}{ Total }} & \multirow[t]{3}{*}{$p$} \\
\hline & \multicolumn{2}{|c|}{ Yes } & \multicolumn{2}{|c|}{ No } & & & \\
\hline & $\mathrm{n}$ & $\%$ & $\mathrm{n}$ & $\%$ & $\mathrm{n}$ & $\%$ & \\
\hline Parity & & & & & & & 0.002 \\
\hline Nulliparous & 16 & 28.6 & 40 & 71.4 & 56 & 100.0 & \\
\hline Parous & 33 & 10.1 & 236 & 72.6 & 325 & 100.0 & \\
\hline Type of delivery & & & & & & & 0.060 \\
\hline Vaginal & 7 & 7.0 & 91 & 93.0 & 98 & 100.0 & \\
\hline Previous cesarean section & 23 & 15.0 & 130 & 85.0 & 153 & 100.0 & \\
\hline Necessity of anesthesia/sedation & & & & & & & 0.006 \\
\hline Yes & 6 & 40.0 & 9 & 60.0 & 15 & 100.0 & \\
\hline No & 43 & 14.0 & 267 & 86.0 & 310 & 100.0 & \\
\hline
\end{tabular}

\section{Discussion}

The women in this study had sociodemographic and reproductive characteristics commonly found in studies evaluating long-term contraceptive methods, as the LNG-IUS.10,16,17

At the time of LNG-IUS insertion, their mean age was $35( \pm 8)$ years old and had between 8-11 years of schooling. A study that followed 61,448 patients over seven years in six European countries recorded a mean age of 37.4 years among women who opted for the LNG-IUS.10 Probably because women in reproductive age group are searching for contraceptive methods with high efficacy and safety. 14,18

In addition, women with higher levels of schooling who are more informed about the safety and efficacy of LARCs and may be more motivated to choose this type of contraception in order to avoid an unplanned pregnancy. Most of the women in this study had eight or more years of schooling, and this level of schooling is similar to PNAD (Pesquisa Nacional por Amostra de Domicílio/National Household Sample Survey) data, which showed an improvement in the educational level in the Brazilian population. ${ }^{19}$ According to the CHOICE contraceptive project, which included 9,256 women from $\mathrm{St}$ Louis region, in the United States (USA), women with less education and financial restrictions had greater difficulty in obtaining contraceptive methods. 18

Although contraception was the most frequent indication for the insertion of the LNG-IUS, other indications are described as high efficacy of the device in the reduction of bleeding and gynecological pathologies treatment. 5 In the present study, some women used the method to treat uterine bleeding, myoma and adenomyosis. Endometriosis associated with pelvic pain and hematological disease were also the reasons to insert the device, according to other studies. $5,7,17$

The use of the LNG-IUS for the treatment of endometriosis associated with pelvic pain is well documented. This treatment is effective in relieving pain, leading to an improvement in the quality of life of women with endometriosis. $5,7,8$ The expansion of the indications for the LNG-IUS insertion is due to its mechanism of action, which promotes endometrial atrophy with consequent control of uterine bleeding and pain. ${ }^{3}$ On the other hand, the LNG-IUS device may present adverse effects that lead women to discontinue the method.20

Among the 327 women in this study, 68 (20.8\%) discontinued the use of the device. The main reason for discontinuation was the device expelled spontaneously $(9.2 \%)$, similar to a study performed with 481 women in the USA whose percentage of spontaneous expulsion was $9.6 \% 16$ and another study carried out in the USA involving 5,403 women using the device with an expulsion rate of $10.1 \% .{ }^{21}$ A 7 year randomized controlled trial in 20 centers in nine countries found a lower expulsion rate $(8.2 \%))^{22}$ It is interesting to observe that this large WHO study 22 was a contraceptive trial where all the women involved had used the LNG-IUS for contraception while in our study there were patients using LNGIUS for gynecological pathologies treatment which may favor the expulsion.

Of the thirty women who expelled the LNG-IUS in our study, the majority had inserted the device for treating metrorrhagia/myoma. This is in line with a study that found a significantly high rate of spontaneous expulsion of the device in women with uterine pathologies. 21 
Discontinuation for bleeding-related complaints occurred in $8(2.4 \%)$ LNG-IUS users. This rate was higher than a trial that assessed 3-year data on the efficacy and safety of a LNG-IUS conducted at 29 clinical sites in the USA (1.5\%). ${ }^{23}$

Besides this, the large WHO study 22 found a cumulative rate of method discontinuation due to bleeding problems higher in the LNG-IUD than the TCu380A group. And also, the increased bleeding volume and frequency were associated with reduced short-term satisfaction in LNG-IUS users among participants. ${ }^{24}$

Most of the women in our study were multiparous, coinciding with data from Youm et al.16 study, in which multiparous women were the majority in the sample. This may be explained because in the past intrauterine devices have been recommended only for women who have already had children. The LNG-IUS expanded the indications for intrauterine devices, including contraception for nulliparous and this indication became more frequently and supported by scientific evidence. $9,11,25$

Parity has also been considered a factor that may be related to the difficulty in insertion of the LNGIUS 9,10 although some studies reported no difficulty in the insertion in nulliparous. 1,11,25 In the present study, the nulliparous tended to experience greater difficulty with the insertion of the LNG-IUS. One explanation for this could be because for many years, the insertion of a copper IUD in nulliparous was contraindicated, 11 which has led to a lower ability of the professionals for inserting the LNGIUS in this group of women.

In this study there was no association between difficulty with insertion of the device and women with previous cesarean section. It is known that the area of scar tissue changes in the isthmus region after cesarean section may hinder the passage of the device during insertions. Although a history of cesarean section is not contraindicated for the LNGIUS insertion, 11 a study compared the difficulty of insertion among women with and without a previous cesarean section found that most of the women who presented difficulty in insertion had a history of cesarean delivery. ${ }^{9}$

It is important to consider the limitations of the present study. Since it is a cross-sectional retrospective study, some medical records were incomplete or illegible.

This study concluded that the main indication for the use of the LNG-IUS was contraception. Most of the women had good adherence to the method, had no difficulty in insertion and did not require anesthesia / sedation.

Randomized and controlled prospective studies evaluating a greater number of women using the LNG-IUS, especially in public hospitals and clinics may produce robust scientific evidence. These results could alert public health managers about the benefits of LNG-IUS in the public service and improve women's health care.

\section{Author's contribution}

Pires MLL, Souza AI, Henriques CV and Ferreira ALCG contributed to the conception and design, analysis, interpretation of the data, and writing of the article. Pires MLL, Dantas MLBR, Soriano GD and Henriques CV contributed to the data collection, analysis, and writing of the article. Souza AI and Ferreira ALCG also contributed to the critical review of the intellectual content. All the authors have approved the final version to be published.

\section{References}

1. Sabbioni L, Petraglia F, Luisi S. Non-contraceptive benefits of intrauterine levonorgestrel administration: why not? Gynecol Endocrinol. 2017; 33: 822-9.

2. WHO (World Health Organization). Family Planning: A global handbook for providers. 2018 Edition. [Cited $10 \mathrm{Jul}$ 2018]. 2018. Available from: http://www.who.int/reproductivehealth/publications/fp-global-handbook/en/

3. Luo L, Luo B, Zheng Y, Zhang H, Li J, Sidell N. Levonorgestrel-releasing intrauterine system for atypical

endometrial hyperplasia. Cochrane Database Syst Rev. 2013; 6: CD009458.

4. Cruz J, Costa AR. Levonorgestrel-releasing intrauterine system and breast cancer. Acta Obstet Ginecol Port. 2017; 11 (4): 276-82

5. Bahamondes L, Bahamondes MV, Shulman LP. Noncontraceptive benefits of hormonal and intrauterine reversible contraceptive methods. Hum Reprod Update. 2015; $21: 640-51$ 
6. Qiu J, Cheng J, Wang Q, Hua J. Levonorgestrel-releasing intrauterine system versus medical therapy for menorrhagia: a systematic review and meta-analysis. Med Sci Monit Basic Res. 2014; 20: 1700-13.

7. Park DS, Kim M La, Song T,. Yun BS, Kim MK, Jun HS, Seong SJ. Clinical experiences of the levonorgestrelreleasing intrauterine system in patients with large symptomatic adenomyosis. Taiwan J Obstet Gynecol. 2015; 5: 412-5

8. WHO (World Health Organization). Medical eligibility criteria for contraceptive use. 5th ed. 2015. WHO Library Cataloguing-in-Publication Data [Cited 21 jul 2017] Available

from: https://apps.who.int/iris/bitstream/handle/10665/181468/97 89241549158_eng.pdf

9. Santos AR, Bahamondes MV, Hidalgo MM, Atti A, Bahamondes L, Monteiro I. Pain at insertion of the levonorgestrel-releasing intrauterine system in nulligravida and parous women with and without cesarean section. Contraception. 2013; 88: 164-8.

10. Heinemann K, Reed S, Moehner S, Do Minh T. Risk of uterine perforation with levonorgestrel-releasing and copper intrauterine devices in the European Active Surveillance Study on Intrauterine Devices. Contraception. 2015; 91: 274-9.

11. Carvalho NS, Botelho AB, Mauro DP, Ferreira KA, Amaro LC, Mendes PC, Savian RR, Carvalho BF. Sexually Transmitted Infections, Pelvic Inflammatory Disease, and the role from Intrauterine Devices: myth or fact? J Biomedical Sci. 2016; 6: 1 .

12. Nascimento R, Hobus D, Jesuíno F, Figueiredo J, Bahamondes L. Evaluation of quality of life and pain control in patients with endometriosis-related pain after insertion of the levonorgestrel-releasing intrauterine system (LNg-IUS). Arq Catarin Med. 2013; 42: 21-7.

13. Liang H, Li L, Yuan W, Zou Y, Gao ES, Duffy JM, Wu SC. Dimensions of the endometrial cavity and intrauterine device expulsion or removal for displacement: a nested case-control study. BJOG. 2014; 121: 997-1004.

14. Secura GM, McNicholas C. Long-acting reversible contraceptive use among teens prevents unintended pregnancy: a look at the evidence. Expert Rev Obstet Gynecol. 2013; 8: 297-9.

15. Pepe C, Sakagute M, Ramos N, Maestri CA. Cost-effectiveness analysis of $52 \mathrm{mg}$ levonorgestrel-releasing intrauterine system (LNG-IUS) versus short-acting hormonal contraceptives in avoiding unintended pregnancy (UP) in 15 to 19 year-old adolescents under the Brazilian Public Healthcare System (SUS). J Bras Econ Saúde. 2017; 9 (1): 100-8.
16. Youm J, Lee HJ, Kim SK, Kim H, Jee BC. Factors affecting the spontaneous expulsion of the Levonorgestrel-releasing intrauterine system. Int J Gynaecol Obstet. 2014; 126: 1659.

17. Bahamondes MV, Hidalgo M, Bahamondes L, Monteiro I. Ease of insertion and clinical performance of the levonorgestrel-releasing intrauterine system in nulligravidas. Contraception. 2011; 84: e11-16.

18. Secura GM, Allsworth JE, Madden T, Mullersman JL, Peipert JF. The Contraceptive CHOICE Project: Reducing Barriers to Long-Acting Reversible Contraception. Am J Obstet Gynecol. 2010; 203: 115.e1-115.e7.

19. Brazil. IBGE (Insituto Brasileiro de Geografia e Estatística). Pesquisa nacional por amostra de domicílios: síntese de indicadores; 2015 / Coordenação de Trabalho e Rendimento. [National survey by sample of households: summary of indicators. 2015 / IBGE, Coordination of Work and Income] Rio de Janeiro: IBGE; 2016. [Cited $25 \mathrm{Jul}$ 2018]. Available from URL:https://biblioteca.ibge.gov.br/visualizacao/livros/liv98 887.pdf

20. Van der Heijden PAHH, Geomini PMAJ, Herman MC, Veersema S, Bongers MY. Timing of insertion of levonorgestrel-releasing intrauterine system: a randomised controlled trial. BJOG. 2017; 124: 299-305.

21. Madden T, McNicholas C, Zhao Q, Secura GM, Eisenberg DL, Peipert JF. Association of age and parity with intrauterine device expulsion. Obstet Gynecol. 2014; 124 : 718-26.

22. Rowe P Farleya T, Peregoudova A, Piaggiob G, Boccarda S, Landoulsic S, Meirikd O, and the IUD Research Group of the UNDP/UNFPA/WHO/World Bank Special Programme of Research. Safety and efficacy in parous women of a 52$\mathrm{mg}$ levonorgestrel-medicated intrauterine device: a 7-year randomized comparative study with the TCu380A. Contraception. 2016; 93: 498-506.

23. Eisenberg DL, Schreiber CA, Turok DK, Teal SB, Westhoff CL, Creinin MD. Three-year efficacy and safety of a new 52-mg levonorgestrel-releasing intrauterine system. Contraception. 2015; 92: 10-6.

24. Dietrish JT, Desai S, Zhao Q, Secura G, Madden T, Peipert JF. Association of Short-term Bleeding and Cramping Patterns with Long-Acting Reversible Contraceptive Method Satisfaction. Am J Obstet Gynecol. 2015; 212 (1): 50.e1-50.e8.

25. Lohr PA, Lyus R, Prager S. Use of intrauterine devices in nulliparous women. Contraception, 2017; 95: 529-53.

Received on November 20, 2019

Final version presented on February 20, 2020

Approved on March 30, 2020 